\title{
Physical Health Literacy and Health-related Behaviors in Patients with Psychosis
}

\author{
Sung-Wan Kim²,3, Woo-Young Park², Min Jhon ${ }^{1,3}$, Mina Kim ${ }^{2,4}$, Ju-Yeon Lee ${ }^{1,2,3}$, Seon-Young Kim, \\ Jae-Min Kim ${ }^{1}$, IL-Seon Shin ${ }^{1}$, Jin-Sang Yoon ${ }^{1}$ \\ ${ }^{1}$ Department of Psychiatry, Chonnam National University Medical School, ${ }^{2}$ Gwangju Mental Health and Welfare Commission, ${ }^{3}$ MindLink, \\ Gwangju Bukgu Community Mental Health Center, ${ }^{4}$ Department of Nursing, Graduate School, Chonnam National University, Gwangju, Korea
}

\begin{abstract}
Objective: This study compared the levels of knowledge of physical illnesses and patterns of health behaviors between patients with psychosis and the general population.

Methods: A total of 712 participants were included in the study; 292 patients with a schizophrenia spectrum disorder and 420 healthy controls matched for age and gender. Questionnaires were administered to study participants to determine the level of knowledge of chronic physical illnesses such as cancer, hypertension, and diabetes mellitus and health-related behavior. Results from the two study groups were compared to identify differences in knowledge of physical illness and health-related behaviors.

Results: Compared with healthy controls, patients with psychosis were less likely to undergo regular medical check-ups and engage in exercise. Patients with psychosis had poorer knowledge of physical illnesses, and were more likely to smoke, be overweight, or have diabetes. Patients with psychosis were significantly less likely to acknowledge the importance of early detection of cancer and controlling hypertension and diabetes, independent of education and type of medical insurance. Patients who smoked were significantly less likely to agree with the statement on the relationship between smoking and physical illnesses. Patients not undergoing regular medical check-ups were significantly less likely to agree with statements concerning the need for cancer screening.

Conclusion: Patients with psychosis demonstrated lower levels of knowledge of physical illnesses and a lack of understanding of preventive behaviors. Low levels of knowledge were associated with poor health-related behaviors. Education of physical health should be provided to patients with psychosis.
\end{abstract}

KEY WORDS: Health; Psychotic disorder; Schizophrenia; Smoking; Neoplasm; Cardiovascular.

\section{INTRODUCTION}

Schizophrenia is a serious psychiatric disorder requiring long-term maintenance therapy and is associated with a high prevalence of various physical illnesses. ${ }^{1)}$ The life

Received: July 17, 2018 / Revised: September 3, 2018

Accepted: October 9, 2018

Address for correspondence: Jin-Sang Yoon, MD, PhD

Department of Psychiatry, Chonnam National University Medical School, 160 Baekseo-ro, Dong-gu, Gwangju 61469, Korea

Tel: +82-62-220-6148, Fax: +82-62-225-2351

E-mail: jsyoon@chonnam.ac.kr

ORCID: https://orcid.org/0000-0002-5903-8164

Sung-Wan Kim, MD, PhD

Department of Psychiatry, Chonnam National University Medical

School, 160 Baekseo-ro, Dong-gu, Gwangju 61469, Korea

Tel: +82-62-220-6148, Fax: +82-62-225-2351

E-mail: swkim@chonnam.ac.kr

ORCID: https://orcid.org/0000-0002-6739-2163 expectancy of patients with schizophrenia is approximately 15 years less than that of the general population. ${ }^{2,3)}$ Patients with severe mental illness, including schizophrenia, have a high level of early mortality. ${ }^{4)}$

High mortality in patients with schizophrenia is primarily due to physical diseases such as cardiovascular disease or cancer. A recent study found cardiovascular disease to be the cause of death in $75 \%$ of cases of patients with schizophrenia. ${ }^{5)}$ Additionally, premature mortality was five times higher in patients with schizophrenia. ${ }^{6)}$ Poor lifestyle choices such as smoking, lack of physical activity, dietary imbalance, side effects of medications, and substance abuse may be contributing factors. ${ }^{3,7,8)}$ When patients with schizophrenia experience symptoms of physical illness or poor health outcomes, such as high blood pressure, glucose, or cholesterol, they are less likely to

(c) This is an Open-Access article distributed under the terms of the Creative Commons Attribution Non-Commercial License (http://creativecommons.org/licenses/by-nc/4.0) which permits unrestricted non-commercial use, distribution, and reproduction in any medium, provided the original work is properly cited. 
seek medical advice and engage in preventive health behaviors. ${ }^{79}$

In particular, smoking is an important issue for patients with schizophrenia, because the smoking rate is higher in this group than in the general population. ${ }^{10)}$ It is well known that smoking is a major risk factor for respiratory and cardiovascular illnesses, as well as various cancers. ${ }^{10)}$ In addition, cigarette smoke interacts with several antipsychotic medications and thus may aggravate the symptoms of schizophrenia. ${ }^{11)}$ Patients with psychosis can find it difficult to quit smoking due to the interaction between nicotine and dopamine, as well as their high levels of dependency and poor psychosocial risk profiles. ${ }^{12)}$ Therefore, in such patients, it is necessary to investigate basic knowledge and beliefs about smoking, to enhance their motivation to quit.

Health literacy is defined as "the capacity of an individual to obtain, interpret, and understand basic health information and services and the competence to use such information and services in ways which are health enhancing". ${ }^{13,14)}$ Health behaviors can be explained according to the knowledge and beliefs that an individual has about an illness. ${ }^{15,16)}$ Knowledge is defined as conditionspecific factual information, whereas beliefs are personal perceptions about a specific health condition or behavior. Enhancement of knowledge and beliefs results in increased understanding of a specific condition or behavior, as well as increased behavior-specific self-efficacy, outcome expectancy, and goal congruence. Such enhancement promotes engagement in self-management health behaviors, which can have a long-term impact on health status. ${ }^{16)}$ In a study of patients with colorectal cancer, those with limited health literacy had less knowledge about cancer and cancer screening, and reported more barriers to the completion of screening examinations. ${ }^{14)}$ In contrast, a cross-sectional study of heart failure patients reported that those with better self-care behaviors had superior knowledge of their illness. ${ }^{17)}$ Furthermore, a meta-analysis of vaccination studies reported that knowledge and risk perception of illness were consistently related to preventive health behaviors. ${ }^{18)}$ Therefore, it appears that evaluation of health knowledge is important, because such knowledge influences health behaviors.

Few studies have investigated knowledge and belief related to physical illness in patients with schizophrenia. We hypothesized that patients with serious mental illness have poor knowledge of physical illness, which consequently leads to unhealthy behaviors. This study assessed knowledge regarding chronic physical illnesses, such as cancer, hypertension, and diabetes, as well as behaviors that promote physical health, in patients with schizophrenia spectrum disorder and the general population.

\section{METHODS}

\section{Participants}

The Gwangju Comprehensive Health Inspection for Mental Illness data set was used for the study. This data set evaluated the physical health of patients with psychotic and mood disorders treated in five community mental health centers in Gwangju, South Korea. Data from patients treated for psychotic disorders were included in the study, while data from patients with a mood disorder without psychotic features were excluded. Of the 302 patients with a psychotic disorder, 10 patients were excluded because of old age ( $>60$ years) or incomplete questionnaire responses. Of the remaining patients, 247 (84.6\%) had schizophrenia, 34 (11.6\%) had affective psychosis, and 11 (3.8\%) had other specified schizophrenia spectrum disorders. All participants were taking antipsychotics. The control group consisted of 420 participants matched for age and gender. Data were collected by mental health workers. This study was conducted from November 2015 to November 2016. The study was approved by the Chonnam National University Hospital Institutional Review Board (CNUH-2015-254).

\section{Measures}

To determine the level of knowledge of chronic physical illnesses such as cancer, hypertension, and diabetes, a literature review was performed to develop a questionnaire. The first five items of the questionnaire are related to perceptions of cancer. These items pertain to the need for early detection and screening of cancer, its causes and risk factors, and the relationship of the disease with smoking. ${ }^{19-23)}$ Six items were related to chronic physical illnesses, such as hypertension and diabetes. ${ }^{24-30)}$ Because an unhealthy lifestyle is common among patients with schizophrenia, three questions were developed to determine the level of knowledge of the relationship of physical illness with exercise and diet. Two further questions 
were related to the need for treatment of hypertension and diabetes. The final item was concerned with smoking as a risk factor for stroke and cardiac disease. Subjects were required to answer 'Yes' or 'No' to each question.

Sociodemographic characteristics including age, gender, education, occupation, marital status, and medical insurance (Medicaid for disadvantaged people and Medicare for the remainder) were recorded. Clinical characteristics including diagnosis of hypertension or diabetes, smoking, exercise, body weight, and routine medical check-up by national insurance in patients were recorded. Overweight was defined as a body mass index $(\mathrm{BMI})>25 \mathrm{~kg} / \mathrm{m}^{2}$.

\section{Statistical Analyses}

Analysis of variance, independent $t$ test, and chisquared test were used to compare sociodemographic and clinical characteristics between patients with psychosis and controls. Questionnaire answers related to physical illness were compared with chi-squared test between the two groups. Logistic regression analysis was used to compare the level of knowledge of physical illnesses and health-related behaviors between the two groups, with adjustment for significant covariates (education and medical insurance). The health-related behavior variables were as follows: regular medical check-up (within the last 2 years; yes or no), exercise (at least once per week; yes or no), and overweight (BMI > $25 \mathrm{~kg} / \mathrm{m}^{2}$; yes or no). Knowledge regarding smoking and the need for routine cancer screening was compared according to current smoking status. Knowledge regarding cancer screening and early detection was compared according to medical check-up status. Knowledge regarding exercise and healthy eating was compared according to overweight status. Because routine medical check-ups are covered by national insurance in Koreans aged 40 years or older, all analyses regarding routine medical check-ups were conducted only in these participants. All statistical tests were two-sided. The $\alpha$-level for statistical significance was 0.05. The collected data were analyzed using the IBM SPSS ver. 23.0 program (IBM Corp., Armonk, NY, USA).

Table 1. Comparison of demographic and clinical characteristics between patients with psychosis and control groups

\begin{tabular}{|c|c|c|c|c|}
\hline Variable & Patient $(n=292)$ & Control $(n=420)$ & $\chi^{2}$ or $\mathrm{t}$ & $p$ value \\
\hline Age $(y r)$ & $40.0 \pm 11.2$ & $39.8 \pm 11.5$ & 0.24 & 0.814 \\
\hline Gender, female & $132(45.2)$ & $196(46.7)$ & 0.18 & 0.670 \\
\hline Education, $>12 \mathrm{yr}$ & $105(36.6)$ & $317(75.5)$ & 107.17 & $<0.001$ \\
\hline Occupation, yes & $53(18.2)$ & $278(67.8)$ & 167.17 & $<0.001$ \\
\hline Marital status & & & 193.61 & $<0.001$ \\
\hline Single & $227(78.3)$ & $154(36.7)$ & & \\
\hline Married & $28(9.7)$ & $256(61.0)$ & & \\
\hline Separated/divorced & $35(12.1)$ & $10(2.4)$ & & \\
\hline Medical insurance, Medicaid & $154(54.6)$ & $41(10.0)$ & 164.78 & $<0.001$ \\
\hline Diagnosis of hypertension & $29(10.2)$ & $27(6.4)$ & 3.36 & 0.067 \\
\hline Diagnosis of diabetes & $35(12.4)$ & $13(3.1)$ & 22.85 & $<0.001$ \\
\hline Smoking & & & 5.03 & 0.081 \\
\hline Current smoker & $66(24.7)$ & $81(19.4)$ & & \\
\hline Ex-smoker & $42(15.7)$ & $53(12.7)$ & & \\
\hline Never smoker & $159(59.6)$ & $284(67.9)$ & & \\
\hline Routine medical check-up* & & & 34.45 & $<0.001$ \\
\hline$>2 \mathrm{yr}$ & $88(61.1)$ & $184(87.6)$ & & \\
\hline $2-10 y r$ & $16(11.1)$ & $10(4.8)$ & & \\
\hline Never & $40(27.8)$ & $16(7.6)$ & & \\
\hline Rigorous exercise & & & 42.18 & $<0.001$ \\
\hline$\geq 3 / w k$ & $34(12.3)$ & $112(27.1)$ & & \\
\hline $1-2 / w k$ & $68(24.6)$ & $141(34.1)$ & & \\
\hline Never & $174(63.0)$ & $160(38.7)$ & & \\
\hline Body mass index, $>25 \mathrm{~kg} / \mathrm{m}^{2}$ & $160(54.6)$ & $101(24.1)$ & 69.09 & $<0.001$ \\
\hline
\end{tabular}

Values are presented as mean \pm standard deviation or number (valid percentage).

*Analysis was conducted in the participants aged 40 years or older $(n=356)$. 


\section{RESULTS}

A total of 712 participants were included in the study. A comparison of demographic and clinical characteristics of patients with psychosis and the control group is included in Table 1. There were no differences in age or gender between the two groups. The control group was significantly more likely to have a higher education level ( $>12$ years), be employed, and be married. Patients in the psychosis group were significantly more likely to be diagnosed with diabetes, be overweight, and have Medicaid insurance. Patients with psychosis were more likely to be diagnosed with hypertension and be current smokers, although the difference was not considered statistically significant. Patients with psychosis were significantly more likely to be current or ex-smokers than the general population $\left(40.4 \%\right.$ and $32.1 \%$, respectively; $\chi^{2}=5.022$, $p=0.025$ ).

Patients with psychosis were significantly less likely to receive routine medical check-ups and engage in rigorous exercise. Of the participants aged 40 years or older $(n=356), 61.1 \%$ with psychosis underwent regular routine medical check-ups provided by the National Health
Insurance Corporation, compared to $87.6 \%$ of the general population; the rate of irregular or zero medical checkups was approximately three times higher in the former subgroup than in the latter $(38.9 \%$ and $12.4 \%$, respectively). Approximately $39 \%$ of participants in the control group and $63 \%$ of patients with psychosis did not engage in regular exercise. More than half of the patients with psychosis were overweight, while less than a quarter of the control group was overweight. The logistic regression analyses of health behaviors and related outcomes adjusted for level of education and medical insurance status also showed significant differences between the two groups. Patients with psychosis showed higher odds ratio (OR) and 95\% confidence interval (95\% $\mathrm{Cl}$ ) of no exercise (OR, 2.62; $95 \% \mathrm{Cl}, 1.79-3.84 ; p<0.001)$, no regular medical check-up (OR, 2.62; $95 \% \mathrm{Cl}$, 1.25-5.48; $p=0.011)$, and overweight $(\mathrm{OR}, 3.94 ; 95 \% \mathrm{Cl}$, $2.67-5.81 ; p<0.001)$, than the general population.

Table 2 presents a comparison of the level of knowledge of physical illnesses between the patient and control groups. Responses were significantly different between the two groups on all five items related to cancer. Patients with psychosis were significantly less likely to acknowl-

Table 2. Comparison of the level of knowledge of physical illnesses between patients with psychosis and control groups

\begin{tabular}{|c|c|c|c|c|c|c|}
\hline \multirow[b]{2}{*}{ Question } & \multicolumn{2}{|c|}{ Agree, n (\%) } & \multirow[b]{2}{*}{$\chi^{2}$} & \multirow[b]{2}{*}{$p$ value } & \multirow{2}{*}{$\begin{array}{l}\text { Adjusted OR* } \\
\quad(95 \% \mathrm{Cl})\end{array}$} & \multirow{2}{*}{$\begin{array}{l}\text { Adjusted } \\
p \text { value }\end{array}$} \\
\hline & $\begin{array}{l}\text { Patient } \\
(\mathrm{n}=292)\end{array}$ & $\begin{array}{l}\text { Control } \\
(\mathrm{n}=420)\end{array}$ & & & & \\
\hline \multicolumn{7}{|l|}{ Knowledge about cancer } \\
\hline If cancer is found early, it is usually possible to treat it. ${ }^{19)}$ & $254(87.0)$ & $410(97.6)$ & 30.97 & $<0.001$ & $0.31(0.14-0.72)$ & 0.007 \\
\hline Cancer occurs in the fate or by the will of sky. ${ }^{20)}$ & $80(27.4)$ & $43(10.3)$ & 35.31 & $<0.001$ & $2.46(1.51-4.01)$ & $<0.001$ \\
\hline $\begin{array}{l}\text { If you do not have any special symptoms, you do not need to } \\
\text { undergo cancer screening. }{ }^{21)}\end{array}$ & $126(43.3)$ & $64(15.2)$ & 69.12 & $<0.001$ & $3.08(2.02-4.68)$ & $<0.001$ \\
\hline $\begin{array}{l}\text { If you have a family member with cancer, you are more likely } \\
\text { to get cancer. }{ }^{22)}\end{array}$ & $186(64.1)$ & $376(89.5)$ & 67.00 & $<0.001$ & $0.25(0.16-0.40)$ & $<0.001$ \\
\hline Smoking can cause various cancers. ${ }^{23)}$ & $237(81.4)$ & $374(89.3)$ & 8.75 & 0.003 & $0.61(0.27-1.02)$ & 0.061 \\
\hline \multicolumn{7}{|l|}{ Knowledge about chronic physical illness } \\
\hline Regular exercise will prevent hypertension and diabetes. ${ }^{24)}$ & $267(91.4)$ & $407(96.9)$ & 10.19 & 0.001 & $0.50(0.22-1.14)$ & 0.101 \\
\hline Eating a lot of salty foods causes hypertension. ${ }^{25)}$ & $230(79.3)$ & $381(90.7)$ & 18.59 & $<0.001$ & $0.43(0.26-0.71)$ & 0.001 \\
\hline Eating a lot of sugar-rich sweet foods causes diabetes. ${ }^{26)}$ & $226(77.7)$ & $320(76.4)$ & 0.16 & 0.688 & $1.05(0.68-1.62)$ & 0.823 \\
\hline $\begin{array}{l}\text { People with high blood pressure or diabetes should take } \\
\text { medication regularly on a daily basis. }{ }^{27,28)}\end{array}$ & $260(89.0)$ & $360(85.7)$ & 1.69 & 0.193 & $1.29(0.74-2.23)$ & 0.372 \\
\hline $\begin{array}{l}\text { If you do not control hypertension/diabetes, you can die from } \\
\text { stroke or heart disease. }\end{array}$ & $231(79.4)$ & $385(92.1)$ & 24.37 & $<0.001$ & $0.47(0.27-0.81)$ & 0.006 \\
\hline $\begin{array}{l}\text { Tobacco smoking increases risk of death by stroke or cardiac } \\
\text { disease. }\end{array}$ & 232 (79.7) & $346(82.6)$ & 0.92 & 0.337 & $0.89(0.56-1.41)$ & 0.620 \\
\hline
\end{tabular}

Values are presented as number (valid percentage).

OR, odds ratio; $95 \% \mathrm{Cl}, 95 \%$ confidence interval.

*Adjusted for education ( $>12$ years) and medical insurance. 
edge the usefulness of screening and the need for early detection of cancer. For example, patients with psychosis were significantly less likely to agree with the statement "if cancer is found early, it is usually possible to treat it", and significantly more likely to agree with the statement "if you do not have any special symptoms, you do not need to undergo cancer screening". Patients with psychosis were also significantly less likely than the control group to acknowledge the need to control hypertension and diabetes, to reduce mortality, by exercising regularly or making healthy diet choices such as reducing salt intake. The logistic regression analyses of questionnaires adjusted for degree of education and medical insurance showed significant differences between the two groups. Six items among eight had statistically significant differences even after controlling for two potentially confounding variables. Patients with psychosis were significantly less likely to acknowledge the need for early detection of cancer and control of hypertension and diabetes, independent of education and medical insurance type.

Figure 1 compares three key items by smoking status in patients with psychosis. Current smokers were significantly more likely to agree with the statement "if you do not have any special symptoms, you do not need to undergo cancer screening" ( $p=0.037)$; fewer agreed with statements "smoking can increase risks of cancer and cardiovascular disease" ( $p=0.001$ and 0.042). Ex-smokers were somewhat more likely to agree with the second statements. Figure 2 shows the results for two key items by

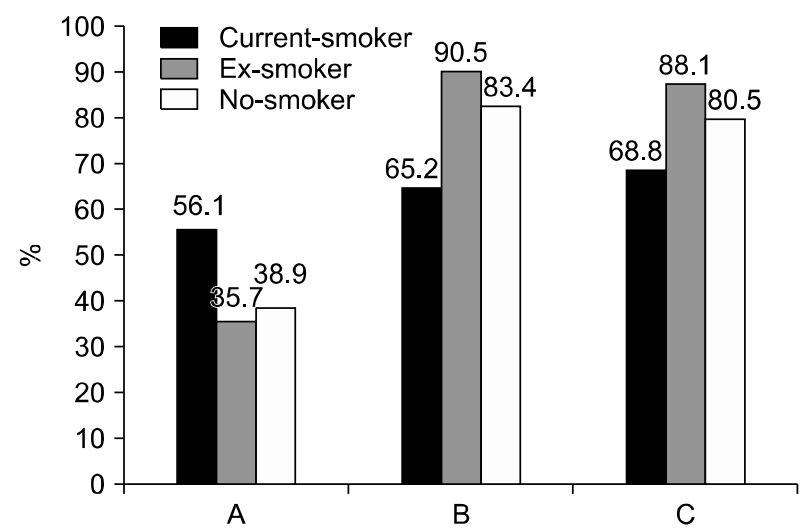

Fig. 1. Comparison of opinions by smoking status in patients with psychosis. (A) If you do not have any special symptoms, you do not need to undergo cancer screening ( $p=0.037$ ). (B) Smoking can lead to many cancers $(p=0.001)$. (C) Tobacco smoking increases risk of death by stroke or cardiac disease $(p=0.042)$. medical check-up status in psychosis patients aged 40 years or older. Patients not regularly attending medical check-ups were significantly less likely to agree with the statement "if cancer is found early, it is usually possible to treat it" ( $p=0.005)$, and were more likely to agree with the statement "if you do not have any special symptoms, you do not need to undergo cancer screening" ( $p=0.048$ ). Figure 3 graphs the responses to two key items by overweight status in patients with psychosis, who were less likely to agree with the statements "regular exercise will prevent hypertension and diabetes" ( $p=0.065)$ and "eating a lot of sugar-rich sweet foods causes diabetes" ( $p=0.029)$.

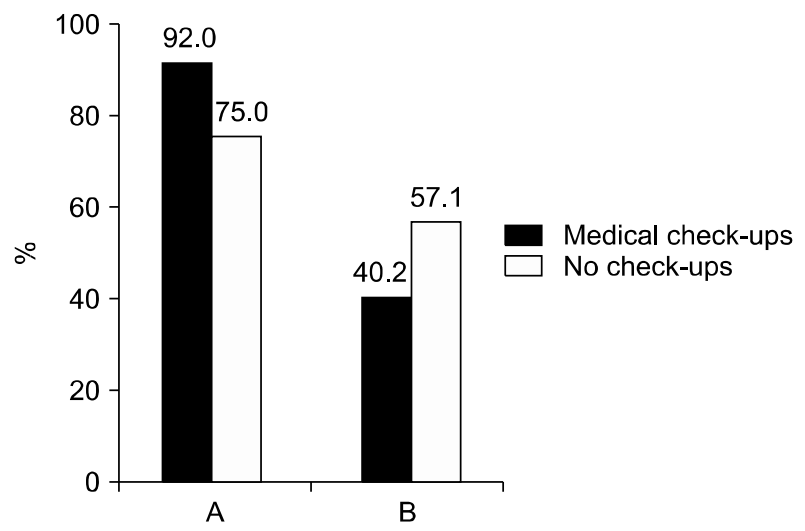

Fig. 2. Comparison of opinions by medical check-up status in psychosis patients aged 40 years or older. (A) If cancer is found early, it is usually possible to treat it $(p=0.005)$. (B) If you do not have any special symptoms, you do not need to undergo cancer screening $(p=0.048)$.

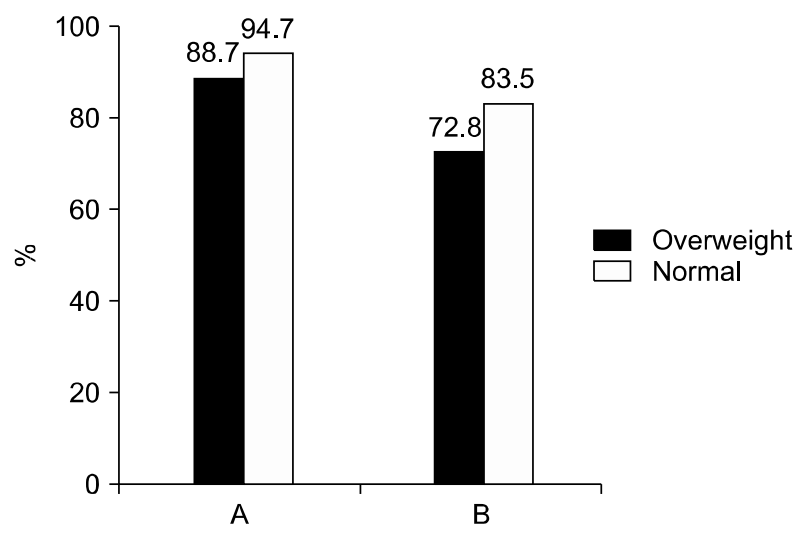

Fig. 3. Comparison of opinions by overweight in patients with psychosis. (A) Regular exercise will prevent hypertension and diabetes $(p=0.065)$. (B) Eating a lot of sugar-rich sweet foods causes diabetes $(p=0.029)$. 


\section{DISCUSSION}

This study evaluated knowledge and perceptions of physical health in patients with psychosis. Compared to healthy controls, patients with psychosis had lower levels of knowledge of physical illnesses such as cancer, hypertension, and diabetes, and a lack of understanding of preventive behaviors. Patients with psychosis generally had poorer physical health status, as they were more likely to be overweight, a current or ex-smoker, and have diabetes. In addition, patients with psychosis were less likely to receive regular medical check-ups and engage in rigorous exercise. These poor health-related behaviors were associated with low levels of physical health literacy. Based on these findings, appropriate education of physical health is strongly recommended for patients with psychosis.

Patients with schizophrenia are more likely to experience physical disorders such as obesity, dyslipidemia, diabetes, hyponatremia, hypertension, cardiovascular disease, stroke, pneumonia, constipation, liver dysfunction, and osteoporosis. ${ }^{31,32)}$ The National Institute for Health and Care Excellence recommends that mental health care providers regularly and systematically monitor weight, waist circumference, pulse, blood pressure, fasting blood glucose, hemoglobin A1c, and blood lipid levels annually in patients treated with antipsychotics. ${ }^{33)}$ In this study, patients with psychosis were significantly less likely to receive routine medical check-ups by national insurance. In addition, patients not undergoing regular medical check-ups were significantly less likely to agree with statements concerning the need for cancer screening. The passive attitude of patients with severe mental illness towards management of physical health may contribute to the low rate of medical check-ups in patients with psychosis.

Interventions to improve the physical health of schizophrenia patients, including modification of lifestyle choices such as smoking, diet, and exercise, have been effective. ${ }^{34)}$ In clinical settings, it may be difficult to engage patients with severe mental illness in behavioral modification due to their low motivation and lack of acknowledgement of the need for physical health management. ${ }^{35)}$ A motivation enhancement strategy is required to change patients' unhealthy behavior. Patients with psychosis displayed a significantly lower level of knowledge of physical health than the general population; more than $40 \%$ of patients with psychosis believed that they did not need regular cancer screening if they did not exhibit specific symptoms. Patients with psychosis do not accurately perceive the potential risks of illness and the need for behavioral change. The lack of knowledge with respect to physical health displayed by patients with psychosis may contribute to a low level of motivation to adopt healthy lifestyle choices. Education regarding the need for early detection and prevention of cancer and cardiovascular illness is required for patients with psychosis.

The poor attitude towards management of physical illness and low use of medical services observed in patients with psychosis may be explained in several ways. Patients with schizophrenia tended to exhibit less concern with physical illness due to the burden of psychotic symptoms. ${ }^{8,36)}$ Patients with schizophrenia were more concerned with the treatment of psychotic symptoms than with general physical health. They were also less concerned about the likelihood of suboptimal physical health or the risk of serious physical illness. ${ }^{8)}$ Symptoms of schizophrenia, such as cognitive decline, social isolation, and paranoid tendencies, may interfere with the recognition and treatment of somatic symptoms. ${ }^{37,38)}$

The stigma of mental illness may also affect the use of medical services by individuals with schizophrenia. ${ }^{1,36)}$ Medical service providers may have a negative attitude and prejudice towards patients with mental illness. ${ }^{5,39)}$ As a result, patients with mental illness may experience unsatisfactory medical care and avoid future medical service utilization.

Patients with severe mental illnesses were not aware of the increased risk associated with physical illness and lacked knowledge of the risk factors for cardiovascular disease and diabetes. ${ }^{8)}$ Low social, economic, and educational levels may also influence the level of knowledge of physical illness. ${ }^{5,40)}$ However, the results of this study demonstrated that patients' acknowledgment of illness was consistently poor independent of educational level and socioeconomic status.

Patients with mental disorders and physical illness may be less likely to quit smoking and have lower smoking cessation success rates than the general population. ${ }^{41)}$ Patients with psychosis who are current smokers may minimize or not recognize the influence of smoking on their health. Current smokers were significantly less likely 
to acknowledge the need for screening; it is strongly recommended that this group receive regular medical check-ups. Patients with psychosis that were ex-smokers were more likely to acknowledge the relationship between smoking and physical illness. Although a causal relationship cannot be demonstrated, greater awareness of the effects of smoking on physical health may encourage patients with psychosis to quit smoking. Appropriate education regarding the negative effects of smoking on physical health is recommended as a smoking cessation strategy. Pharmacotherapy combined with behavioral treatment was effective for patients with mental disorders. ${ }^{41)}$ A variety of systematic strategies should be developed to help patients with psychosis quit smoking. ${ }^{42)}$

This study has several limitations that may limit the generalizability of results. Questionnaires were not validated for physical illness and healthy lifestyles, and were generally accepted as common sense for health. Formal scales for psychotic symptoms and social functioning were not administered. The study population was limited to patients who used a mental health center in a metropolitan city, which may have introduced a selection bias. However, evaluating the knowledge of and attitudes toward physical illness and healthy lifestyles may contribute to a greater understanding of the underlying causes of poor management of physical health in patients with psychosis.

Despite higher mortality rates and shorter life expectancies, patients with psychosis were less likely to acknowledge the need for regular medical check-ups and healthy lifestyle choices. Furthermore, low levels of knowledge were associated with poor health-related behaviors in patients with psychosis. Mental health providers must overcome the mind-body dualism and account for the fact that patients with psychosis may not possess a level of common-sense health knowledge present in the general population. Appropriate information regarding physical illness and healthy behaviors should be provided to patients with psychosis. Further research is required to determine if improving attitudes toward, and knowledge of, physical illness contributes to promoting adoption of healthy lifestyle behaviors.

\section{- Acknowledgments}

This study was supported by a grant of the Korean Mental Health Technology R\&D Project, Ministry of
Health \& Welfare, Republic of Korea (HM15C1140). This research work was conducted as part of the Gwangju Mental Health Demonstration Project supported by Ministry of Health \& Welfare and Gwangju Metropolitan City, Republic of Korea.

\section{REFERENCES}

1. Piotrowski P, M Gondek T, Królicka-Deręgowska A, Misiak B, Adamowski T, Kiejna A. Cause of mortality in schizophrenia: an updated review of European studies. Psychiatr Danub 2017;29:108-120.

2. Bitter I, Czobor P, Borsi A, Fehér L, Nagy BZ, Bacskai M, et al. Mortality and the relationship of somatic comorbidities to mortality in schizophrenia: a nationwide matched-cohort study. Eur Psychiatry 2017;45:97-103.

3. Marder SR, Essock SM, Miller AL, Buchanan RW, Casey DE, Davis JM, et al. Physical health monitoring of patients with schizophrenia. Am J Psychiatry 2004;161:1334-1349.

4. Saha S, Chant D, McGrath J. A systematic review of mortality in schizophrenia: is the differential mortality gap worsening over time? Arch Gen Psychiatry 2007; 64:1123-1131.

5. Liu NH, Daumit GL, Dua T, Aquila R, Charlson F, Cuijpers P, et al. Excess mortality in persons with severe mental disorders: a multilevel intervention framework and priorities for clinical practice, policy and research agendas. World Psychiatry 2017;16:30-40.

6. Mas-Expósito L, Mazo AE, San Emeterio M, Teixido M, Lalucat-Jo L. Physical health and schizophrenia in clinical practice guidelines and consensus statements. J Addict Res Ther 2012;58:001.

7. Roberts L, Roalfe A, Wilson S, Lester H. Physical health care of patients with schizophrenia in primary care: a comparative study. Fam Pract 2007;24:34-40.

8. Buhagiar K, Parsonage L, Osborn DP. Physical health behaviours and health locus of control in people with schizophrenia-spectrum disorder and bipolar disorder: a cross-sectional comparative study with people with non-psychotic mental illness. BMC Psychiatry 2011;11:104.

9. Holmberg SK, Kane C. Health and self-care practices of persons with schizophrenia. Psychiatr Serv 1999;50:827-829.

10. Lambert TJ, Velakoulis D, Pantelis C. Medical comorbidity in schizophrenia. Med J Aust 2003;178 Suppl:S67-S70.

11. Šagud M, Vuksan-Ćusa B, Jakšić N, Mihaljević-Peleš A, Rojnić Kuzman M, Pivac N. Smoking in schizophrenia: an updated review. Psychiatr Danub 2018;30(Supp/ 4):216-223.

12. Robson D, Gray R. Serious mental illness and physical health problems: a discussion paper. Int I Nurs Stud 2007;44:457466.

13. Joint Committee on National Health Education Standards. National health education standards: achieving health literacy. Reston, VA:Association for the Advancement of Health Education; 1995. 
14. Peterson NB, Dwyer KA, Mulvaney SA, Dietrich MS, Rothman $\mathrm{RL}$. The influence of health literacy on colorectal cancer screening knowledge, beliefs and behavior. J Nat/ Med AssoC 2007:99:1105-1112.

15. Becker MH. The health belief model and personal health behavior. Health Educ Monogr 1974;2:324-473.

16. Ryan P. Integrated theory of health behavior change: background and intervention development. Clin Nurse Spec 2009; 23:161-170.

17. Liu MH, Wang CH, Huang YY, Cherng WJ, Wang KW. A correlational study of illness knowledge, self-care behaviors, and quality of life in elderly patients with heart failure. J Nurs Res 2014;22:136-145.

18. Brewer NT, Chapman GB, Gibbons FX, Gerrard M, McCaul KD, Weinstein ND. Meta-analysis of the relationship between risk perception and health behavior: the example of vaccination. Health Psychol 2007;26:136-145.

19. Breslow L, Cumberland WG. Progress and objectives in cancer control. JAMA 1988;259:1690-1694.

20. Cullen JW. Design of cancer prevention studies. Cancer Detect Prev 1986;9:125-138.

21. Naruke T, Kuroishi T, Suzuki T, Ikeda S. Comparative study of survival of screen-detected compared with symptom-detected lung cancer cases. Japanese Lung Cancer Screening Research Group. Semin Surg Oncol 1993;9:80-84.

22. Ramsey SD, Yoon P, Moonesinghe R, Khoury MJ. Populationbased study of the prevalence of family history of cancer: implications for cancer screening and prevention. Genet Med 2006; 8:571-575.

23. Danaei G, Vander Hoorn S, Lopez AD, Murray CJ, Ezzati M; Comparative Risk Assessment collaborating group (Cancers). Causes of cancer in the world: comparative risk assessment of nine behavioural and environmental risk factors. Lancet 2005;366:1784-1793.

24. Whelton SP, Chin A, Xin X, He J. Effect of aerobic exercise on blood pressure: a meta-analysis of randomized, controlled trials. Ann Intern Med 2002;136:493-503.

25. Cook NR, Cutler JA, Obarzanek E, Buring JE, Rexrode KM, Kumanyika SK, et al. Long term effects of dietary sodium reduction on cardiovascular disease outcomes: observational follow-up of the trials of hypertension prevention (TOHP). BMJ 2007;334:885-888.

26. Schulze MB, Manson JE, Ludwig DS, Colditz GA, Stampfer MJ, Willett WC, et al. Sugar-sweetened beverages, weight gain, and incidence of type 2 diabetes in young and middle-aged women. JAMA 2004;292:927-934.

27. James PA, Oparil S, Carter BL, Cushman WC, DennisonHimmelfarb C, Handler J, et al. 2014 evidence-based guideline for the management of high blood pressure in adults: report from the panel members appointed to the Eighth Joint National Committee (JNC 8). JAMA 2014;311:507-520.

28. Chobanian AV, Bakris GL, Black HR, Cushman WC, Green $\mathrm{LA}$, Izzo JL Jr, et al. The seventh report of the Joint National
Committee on prevention, detection, evaluation, and treatment of high blood pressure: the JNC 7 report. JAMA 2003; 289:2560-2572.

29. Sowers JR, Epstein M, Frohlich ED. Diabetes, hypertension, and cardiovascular disease: an update. Hypertension 2001; 37:1053-1059.

30. Ockene IS, Miller NH. Cigarette smoking, cardiovascular disease, and stroke: a statement for healthcare professionals from the American Heart Association. American Heart Association Task Force on Risk Reduction. Circulation 1997;96:32433247.

31. Correll CU, Detraux J, De Lepeleire J, De Hert M. Effects of antipsychotics, antidepressants and mood stabilizers on risk for physical diseases in people with schizophrenia, depression and bipolar disorder. World Psychiatry 2015;14:119-136.

32. Karadag F, Sengul CB, Enli Y, Karakulah K, Alacam H, Kaptanoglu B, et al. Relationship between serum bilirubin levels and metabolic syndrome in patients with schizophrenia spectrum disorders, Clin Psychopharmacol Neurosci 2017; 15:153-162.

33. National Institute for Clinical Excellence. Psychosis and schizophrenia in adults: prevention and management. NICE guidelines [CG178], 2014. London:National Institute for Clinical Excellence;2014.

34. Baker A, Kay-Lambkin FJ, Richmond R, Filia S, Castle D, Williams J, et al. Study protocol: a randomised controlled trial investigating the effect of a healthy lifestyle intervention for people with severe mental disorders. BMC Public Health 2011;11:10.

35. Sugawara N, Yasui-Furukori N, Yamazaki M, Shimoda K, Mori T, Sugai T, et al. Attitudes toward metabolic adverse events among patients with schizophrenia in Japan. Neuropsychiatr Dis Treat 2016;12:427-436.

36. Swildens W, Termorshuizen F, de Ridder A, Smeets $H$, Engelhard IM. Somatic care with a psychotic disorder. Lower somatic health care utilization of patients with a psychotic disorder compared to other patient groups and to controls without a psychiatric diagnosis. Adm Policy Ment Health 2016;43: 650-662.

37. Phelan M, Stradins L, Morrison S. Physical health of people with severe mental illness: can be improved if primary care and mental health professionals pay attention to it. BMJ 2001; 322:443-444.

38. Tripathi A, Kar SK, Shukla R. Cognitive deficits in schizophrenia: understanding the biological correlates and remediation strategies. Clin Psychopharmacol Neurosci 2018; 16:7-17.

39. Corrigan PW, Mittal D, Reaves CM, Haynes TF, Han X, Morris $\mathrm{S}$, et al. Mental health stigma and primary health care decisions. Psychiatry Res 2014,218:35-38.

40. van Hasselt FM, Schorr SG, Mookhoek EJ, Brouwers JR, Loonen AJ, Taxis K. Gaps in health care for the somatic health of outpatients with severe mental illness. Int J Ment Health 
Nurs 2013;22:249-255.

41. Chacón F, Mora F, Gervás-Ríos A, Gilaberte I. Efficacy of lifestyle interventions in physical health management of patients with severe mental illness. Ann Gen Psychiatry 2011;10:22.
42. Na E, Roh S. Treatment of tobacco use disorders in people with mental illness. J Korean Soc Res Nicotine Tob 2015;6:7885. 